\title{
GENDER, RACE AND STRESS AMONGST WOMEN IN MANAGEMENT
}

\section{Gourie Suraj-Narayan}

\section{INTRODUCTION}

For decades a patriarchal system precluded women from having a legal or political identity, and the legislation and attitudes supporting a patriarchal society provided the model for slavery. By the middle of the $20^{\text {th }}$ century the emphasis had shifted from the oppression of women to establishing social and economic equality in the work and family sphere, and the women's movement that sprung up during the 1960s began to argue that women were oppressed by patriarchal structures. Theories to explain how gender and racial inequalities in management have their roots in ideologies based on gender and racial differences, and feminist theoretical concepts of patriarchy challenge these inequalities. They do this by challenging concepts of gender, race, the family and the unequal division of labour underpinned by a theory of patriarchy that has come to reveal how it operates to subordinate women and privilege men, often at women's expense. Thus patriarchy operates to achieve and maintain the gender and racial inequalities essential for the subordination of women. Another factor that impedes female managers' access to top-level jobs is women's own career strategies and ambivalent attitude towards a "masculine type" career orientation characterised by competition over power. This ambivalent attitude can be attributed to the tensions felt by female managers endeavouring to maintain a balance between professional and family responsibility.

In terms of perceived effectiveness, according to their peers and subordinates, female managers outperformed men on six out of seven dimensions of managerial behaviour in a study conducted by Perrault and Irwin (1996). The female managers outperformed the male managers not only on the interpersonal factors, but especially in "controlling". According to Davidson and Burke (2000:130), there are few consistent gender differences in personality, managerial behaviour and effectiveness, despite the persistent stereotypes about gender differences. They indicate that there are in fact no reasons for not promoting women who are both motivated and capable of performing as a manager into top management positions. This viewpoint has potentially the same impact on the advancement of women into management positions as the feminisation of management phenomenon.

\section{LEGISLATIVE MEASURES PROMOTING RACIAL AND GENDER EQUITY}

Building an anti-racist and anti-sexist South Africa is one of the major goals of our democratic dispensation. Since 1994 a number of developments have created a structural framework promoting the goal of gender and racial equality. The key affirmative action legislation in South Africa is the Employment Equity Act 55 of 1998. The former president of South Africa, Thabo Mbeki, supported the promotion of the Equality and Prevention of Unfair Discrimination Act on 9 February 2000. The Act promotes equality, prevents unfair discrimination and prohibits "hate speech". In its preamble the Act emphasised the need to eradicate the inequalities in South African society, particularly those that were generated by colonialism, apartheid and patriarchy. Among other things, the Act prohibited unfair discrimination on the basis of sex and race. 
According to the Department of Labour (1998) the purpose of the Act is to achieve equity in the workplace by:

- promoting equal opportunity and fair treatment in employment through the elimination of unfair discrimination;

- implementing affirmative action measures to redress the disadvantages in employment experienced by designated groups;

- by ensuring their equitable representation in all occupational categories and levels in the workforce.

These developments are exciting and important in their own right, but it is also necessary to examine more closely the mechanics of transforming cultural and organisational practices that mitigate against the advancement of women into management. The Businesswomen's Association (BWA) together with Catalyst, a businesswomen's organisation in the United States, have put together the South African Women in Corporate Leadership Census 2004. The census found that, although women make up just over half $(52 \%)$ of the working South African population, only $14.7 \%$ of all executive managers and only $7.1 \%$ of all directors in the country are women. This means that women fill less than a quarter of all of these top positions in South Africa. For the JSE-listed companies, the census reveals that out of the 3.125 directorship positions, women hold only 221 . Out of 364 chair positions, only 11 were women. Also there are only seven women CEOs/MDs, while 357 positions are filled exclusively by men. As entrants to a traditionally male-dominated career path, female managers are experiencing the impact of racial and gender discrimination in the workplace.

An audit of women and men in South African newsrooms, a project of the South African National Editors Forum (SANEF) conducted in collaboration with Gender Links, involved administering a factual questionnaire to the media, SABC, Citizen, Kaya FM, Media 24, Primedia, SAPA, the Independent Group of newspapers, Johncom and the Mail and Guardian between September and December 2006. According to Morna (2009), this study, which covered 4364 employees, revealed a host of barriers to the advancement of women in the media profession. It found that, despite a South African constitution that entrenches equal rights, "discriminatory practices, structural inequalities, cultural factors, prejudices, patriarchy and sexism were still alive and well in our South African newsrooms". The annual average salary of women in a South African newsroom is R184,387 per annum, which is $21 \%$ less than the average annual salary of men (R233,737). While the income differential between white men and black men in newsrooms is narrowing, black women earn on average $25 \%$ less than white men in newsrooms. These salary figures, more than any thing else, reflect the gender gaps in newsrooms. In South Africa women occupy less than $30 \%$ of top management posts and make up one out of three senior managers in newsrooms. Conversely, they comprise $48 \%$ of junior managers and almost $70 \%$ of all semi-skilled workers. While black men constituted $16 \%$ of top and senior managers in newsrooms in 1999 in 2006, this percentage has increased to $23.5 \%$. On the other hand, black women account for a mere $6 \%$ of top and senior management in newsrooms. While there are now roughly equal proportions of women and men in the editorial divisions of newsrooms, women dominate the presenter and lowest-paying administrative categories, while men make up $86 \%$ of the better-paid technical category.

Gender discrimination is clearly prohibiting South Africa's women journalists from realising their potential. Despite post-apartheid progress, lack of fair and open access to the labour market hinders progress toward the reduction of racial and gender disparities in economic 
status. Although policy-makers argue that not all disadvantages should be attributed to discrimination of any kind, the disadvantages and discrimination faced by women and Africans are severe by international standards. It is against this background that this study was undertaken to examine the stressors arising from gender and race issues as part of a broader study on women in management and occupational stress.

\section{RESEARCH METHOD}

A descriptive design was used which portrayed the unique characteristics of the population more accurately. It also allowed for an inductive, subjective and process-oriented worldview. Both qualitative and quantitative methods of data collection were used in this study. The biographical questionnaire was used to collect data on the profile of the respondents and the organisations. A semi-structured interview schedule was used to elicit information on the sources of stress and its manifestations, and the interventions used to cope with stress. The geographical area of study was Durban and the surrounding areas extending to Phoenix in the North and Hammarsdale in the West. Non-probability sampling was used to select a sample of 30 female managers.

\section{RESULTS AND DISCUSSION}

\section{Demographic profile of respondents}

\section{Racial background}

In keeping with South Africa's multicultural demographics, women managers from diverse racial backgrounds were selected. The racial background of the respondents is reflected in Table 1.

TABLE 1

RACIAL BACKGROUND OF RESPONDENTS

\begin{tabular}{|l|c|c|}
\hline Racial background & Number & \% \\
\hline African & 10 & 33.3 \\
\hline Indian & 10 & 33.3 \\
\hline Caucasian & 10 & 33.3 \\
\hline Total & $\mathbf{3 0}$ & $\mathbf{1 0 0}$ \\
\hline
\end{tabular}

Table 1 reflects an even distribution of African, Indian and Caucasian respondents.

\section{Age of respondents}

The age of the respondents is reflected in Table 2.

TABLE 2

\section{AGE OF RESPONDENTS}

\begin{tabular}{|l|c|c|}
\hline Age & Number & \% \\
\hline Under 30 & 1 & 3 \\
\hline $30-39$ & 14 & 47 \\
\hline $40-50$ & 15 & 50 \\
\hline Total & $\mathbf{3 0}$ & $\mathbf{1 0 0}$ \\
\hline
\end{tabular}

It is evident from Table 2 that an even distribution of respondents was below 40 years. This trend of appointing younger women to managerial positions may be in response to the affirmative action policy of equalising opportunities for women. 


\section{Marital status of respondents}

The marital status of the respondents has a significant bearing on the nature of stressors they experience. The majority of the respondents $(80 \%)$ were married. Only a small proportion of the respondents (20\%) were single. Similarly, in the United Kingdom Davidson (1997) found that $70 \%$ of the black and ethnic minority women managers were married or living with someone.

Being married has implications in terms of the stressors that women managers experience. As one respondent commented, "marriage increased the number of hours of housework for me as I had to take care of my husband and clean up after him".

Professional women are caught between a rock and a hard place. They are told: "If you want to get ahead for success, you better not get married and have kids" (Vinnicombe, 2000:17). However, in spite of the demands of married life, it is evident from the present findings that women managers are forging ahead with their careers.

\section{Type of family system of respondents}

The types of family systems that respondents belonged to are reflected in Table 3.

TABLE 3

TYPE OF FAMILY SYSTEM

\begin{tabular}{|l|c|c|}
\hline Family systems & Number & $\%$ \\
\hline Nuclear Family & 26 & 86.7 \\
\hline Extended Family & 4 & 13.3 \\
\hline Total & $\mathbf{3 0}$ & $\mathbf{1 0 0}$ \\
\hline
\end{tabular}

Table 3 reflects that the majority of the respondents $(86.7 \%)$ have moved away from the traditional extended family system to a nuclear family system. Only a small proportion of the respondents (13.3\%) lived in an extended family system. The extended family has largely made way for the nuclear family, which poses significant challenges for women managers struggling to perform family roles, manage their jobs as well as maintain their relationships within the family. The respondents indicated that living in an extended family system provided the supportive frameworks in terms of household division of labour, childcare and additional incomes. Similarly, Davidson (1997) found that the extended family support system acted as an important stress buffer for her sample of black and ethnic minority women managers.

\section{Number of children}

The present findings are reflected in Table 4.

TABLE 4
NUMBER OF CHILDREN
\begin{tabular}{|l|c|c|}
\hline Children & Number & $\%$ \\
\hline 0 & 4 & 13.3 \\
\hline $1-2$ & 22 & 73.3 \\
\hline $3-4$ & 4 & 13.3 \\
\hline
\end{tabular}

Table 4 shows that $86.6 \%$ of the respondents have children. A larger proportion of the respondents had between one to two children. Similarly Davidson (1997) found that $60 \%$ of the black and ethnic minority women managers had between one to four children. Research in the UK by the British Institute of Management (Vinnicombe, 2000) showed that 50\% of the 
women managers had children. In West Germany the majority of the women managers had only one child (Vinnicombe, 2000).

Combining work with child rearing is very stressful for most women. However, Pillay (2000) found that even with a smaller family size $65 \%$ of working women in her study in South Africa could not cope with the needs and demands of their children. The transition from the marital dyad to the family triad is a significant one. The strain of parenthood can be overwhelming. Thus the number of children women managers have impacts on the stressors they experience in balancing work/family life.

\section{Educational level}

The educational levels of the respondents are reflected in Table 5.

TABLE 5

EDUCATIONAL LEVEL OF RESPONDENTS

\begin{tabular}{|l|c|c|}
\hline Educational level & Number & \% \\
\hline Postgraduate degree & 12 & 40 \\
\hline Degree & 12 & 40 \\
\hline Diploma & 4 & 13.3 \\
\hline Matriculation & 2 & 6.7 \\
\hline Total & $\mathbf{3 0}$ & $\mathbf{1 0 0}$ \\
\hline
\end{tabular}

Table 5 shows that the majority of the respondents $(80 \%)$ had a high level of education, including university degrees and postgraduate degrees. Similarly, Davidson (1997) found that there was an increasing trend for women graduates to move into areas of managerial and professional employment, which were previously dominated by men.

\section{Nature of employment}

The nature of employment of the respondents is reflected in Table 6.

TABLE 6

\section{NATURE OF EMPLOYMENT}

\begin{tabular}{|l|c|c|}
\hline Nature of employment & Number & $\%$ \\
\hline Employed in public sector & 15 & 50 \\
\hline Employed in private sector & 15 & 50 \\
\hline Senior management position & 3 & 10 \\
\hline Lower management Position & 27 & 90 \\
\hline Duration of employment as manager: less than 5 years & 28 & 90.3 \\
\hline
\end{tabular}

The assessment of management grades was left to the respondent's discretion. Ninety percent of the respondents interviewed identified themselves as being in lower management positions. They were responsible for the supervision of the subordinates and management of specific departments and projects. Only $10 \%$ of the respondents were in senior management positions. They were responsible for the managers and reported directly to the directors of the company. The present findings reflect that, while women are able to gain entry into managerial positions, it is still difficult for them to reach upper and middle management positions. The majority of the respondents were in managerial positions for less than five years, which could be the result of affirmative action policies. 


\section{Organisational culture}

All the respondents identified organisational cultures as significant sources of stress. The respondents indicated that, although their organisations are becoming increasingly diverse, the predominant paradigm for educating and managing the new work force has remained rooted in an exclusively male mindset. Female respondents' concerns were centred on the management development and training programmes designed to empower female managers, but ironically had a tendency to encourage women to "think manager, think male".

Among processes which tended to discriminate against women managers, the respondents indicated that the following negative masculine organisational cultures tended to favour men:

- entry to managerial posts was no longer competence based but power based with the top power structures remaining masculine clubs;

- persistent stereotypes related to career paths or positions "suited" to women;

- implicit co-optation processes which determined access to executive positions - this tended to favour men;

- the marginalisation of women managers at the top is likely to stem from a complex interaction of sex role stereotyping and male-norm organisational practices which reinforced a macho corporate culture.

As one respondent commented: "An inhospitable corporate culture was a key to barrier to my advancement - failure to have my contributions recognised, not being taken seriously, being excluded from team work, lack of recognition of my talents, lack of autonomy and the continuation of the "old boys club'."

Another concern noted by a respondent with two children was that: "One of the factors that has impeded my progress to the top level executive positions was my ambivalent attitude towards a 'masculine' type of career orientation which did not endeavour to maintain a balance between professional and family responsibilities. So if I chose to progress higher up the ladder, the less time I would have spent with my family - which is an unfair choice for me. I want a balance between both my worlds of work and family".

The implicit assumption was that the respondents would only succeed if they adopted the characteristics of effective male managers and masculine leadership styles. The constantly reinforced message is that women can succeed only if they become more assertive, competitive, "dressed for success" and more politically and socially astute, which is unfortunately also the case in South Africa (Swanepoel, 2000:394).

\section{Glass ceiling}

The glass ceiling is not simply a barrier for an individual, based on the person's inability to handle a higher-level job. Rather the glass ceiling applies to women as a group who are kept from advancing higher because they are women. The majority of the respondents (80\%) indicated that they experienced a glass ceiling which hindered upward mobility. Within the organisation, the respondents indicated that they did not have the opportunities to gain the experiences needed to advance in the organisation and were not given assignments that would make them good candidates for higher-level positions.

One of the concerns noted was: "In my organisation only the male managers are given national and international assignments. It is assumed that because I have two children below five years 
of age that I would not be able to meet these responsibilities. I feel very frustrated and stressed out as this is preventing me from moving up the ladder".

Discrimination on the basis of gender is illegal, so other reasons must be given for the glass ceiling that results in women's absence at the top of the corporate ladder. The following are some of the most common explanations for women's stagnation at lower organisational levels:

- Person-centred explanations suggest that socialisation practices directed towards females encouraged the development of personality traits, skills and behaviours that are contrary to the demands of the managerial role (Powell, 2000);

- In contrast, situation-centred explanations suggest that the nature of the work environment faced by women who aspire to management positions determines their fate rather than their traits, skills and behaviours (Powell, 2000).

\section{Effort-reward imbalance}

There is consistent evidence of an association between subjective reports of the state of one's psychological contract and the implicit expectations female managers and organisations have about their remunerations, benefits, rewards, etc. The following stressors were identified by the respondents:

- To work harder and be more committed than their male colleagues because of performance pressure arising out of their gender and race $(60 \%)$;

- Fewer incentives than their colleagues who had company cars, etc. (80\%);

- Long working hours - detrimental to health of women with heavy domestic workloads $(100 \%)$

- Income inequality $(70 \%)$;

- Feeling undervalued $(80 \%)$.

One of the concerns noted by a respondent was that: "I feel like I am worth nothing as I am totally undervalued. This is evident in the way my male colleagues are rewarded for the same work I do. They receive higher salaries and they have company cars, whereas I do not receive these benefits."

The findings are congruent with the effort-reward imbalance model as developed by Siegrist (1999). According to Siegrist (1999), people experience emotional distress when they are not rewarded for the efforts they put into their work. A perceived lack of justice when women are not treated equally in the workplace also has a negative impact on the women's health in modern life. When women do not receive the same salary as men for doing the same job, this leads to conflict and a breakdown in relationships at work. This also has negative health consequences (Wilkinson, 1996). Effort-reward imbalance and over-commitment are found to be important in explaining adverse health effects such as gastrointestinal disorders, psychiatric disorders and poor subjective health (Siegrist \& Peter, 2000).

\section{Employee job control and decision latitude}

Employee job control and decision latitude can moderate or reduce job strain. Decision latitude or the ability to organise one's own tasks is considered central to reducing the strain and stress caused by jobs. The following sources of stress were identified by the respondents:

- Low level of job control (80\%);

- Lack of decision-making power $(70 \%)$; 
- Feeling powerless $(70 \%)$.

Some of the concerns expressed by the respondents with regards to employee job control and decision latitude were:

I find it very stressful working in a company which does not value the work I do. Although I am the head of the Employee Assistance Programme, the management always brings in outside consultants (white males) to develop and implement programmes for the staff without consulting with me (African female manager).

Our services are under-utilised and undervalued because we are a female-dominated department. I think being black and being female has a lot to do with the attitudes of staff and management.

My boss and my subordinates do not listen to what I have to say at meetings. I feel I do not have any power to deal with staff nor bring about any changes in the organisation (Caucasian female manager).

I am the only female in a boardroom full of men. My decisions and contributions are not taken seriously. My contributions are always undermined by my male superiors. My male colleagues do not support me either, yet I bring in the most amount of profit for the company.

\section{Insubordination by staff}

During the apartheid era the majority or almost all managerial positions were held by Caucasian males. Since the introduction of affirmative action policies organisations have had to give priority to African and Indian women being employed in managerial positions. However, the consequences of such actions are reflected as follows:

- Insubordination by male staff $(90 \%)$;

- Refusal by African subordinates to work "under" a female (90\%).

The following concerns were noted:

One of the white employees who was due for a promotion declined the promotion as he refused to be under me (African female manager).

The white employees do not follow the proper channels of communication and often bypass me and consult directly with the directors. I cannot question this as the white directors condone this behaviour and this makes me feel very inadequate (Indian female manager).

Some of the white subordinates resent being managed by us. There is lack of respect for us as managers and we are not taken seriously (African female manager).

\section{Gender role stereotypes}

Managerial power is both hierarchical and gendered. Typically, it is in the managerial functions that organisational power resides formally (or informally). Managerial prerogative can be seen as part of a highly masculine discourse. Thus, as entrants to a non-traditional career field, female managers encountered a number of external barriers, as discussed earlier. They experienced unique barriers as a function of their level or managerial rank. One of the major career barriers was the continued biased attitude towards the respondents based on gender stereotyping of the managerial position. Both the public and private organisations were dominated by gender-related values that biased organisational life in favour of male managers. 
Favouritism of male counterparts increased the respondent's vulnerability to stress. Some of the stressors identified by the respondents with regard to gender stereotyping were:

- Stereotypical attitude of the management position: "Think manager, think male" (100\%);

- Women are not suited to managerial positions ... they are incapable of doing a man's job $(90 \%)$;

- Refusal by black subordinates to work "under" a female manager (90\%);

- Management's perception that women are more committed to family than work (100\%);

- Women managers are not career committed due to family obligations (90\%).

Such stereotypes led respondents to believe that they were unprepared for careers in management. Because of the considerable public scrutiny experienced by female managers, the respondents indicated that female staff tried to avoid failures by minimising risk-taking and continuing to work in lower-level positions. The social division of gender and its associated forms of oppression produced a situation in which the respondents faced additional pressures and stressors. The specific stressors identified by the respondents were:

- Sexist comments $(70 \%)$;

- Limited access to power, resources and promotion $(80 \%)$;

- Strains of coping with prejudice and sex stereotyping (100\%);

- Overt and indirect discrimination from fellow employees based on gender $(100 \%)$.

Some of the concerns noted were:

Being the head of a "female-dominated" department I am not included in the organogram in line with the male managers.

I have been accused of sleeping my way to the top because I am the only female manager.

My management still has the master-servant mentality. They treat me like a maid and I have to clean up after them.

Most of the products in my company are not women-friendly. Being a marketing manager I have tried to motivate for the female consumers' needs to be taken into account, but this has been ignored. I bring in fifty million rand in profits for the company, but this is not acknowledged just because I am the only female among a white male-dominated management.

The fact that my organisation is based on male models of work is discriminatory against women.

It is evident from the present findings that stereotypical attitudes of the managerial positions, cultural norms as well as subtle discrimination were potential sources of stress for the majority of the respondents. The sexism that the respondents encountered highlights what Hanner and Statham (1988) describe as the "double jeopardy" of being a female manager: the challenge of succeeding in a male-dominated world without reinforcing, or becoming part of it. This male ethos in organisations becomes an additional stressor for women managers (Davidson \& Burke, 2000).

\section{Tokenism}

Although the affirmative action programmes are based on the need to rectify past injustices of the under-representation of women in management positions, these programmes have also 
unintentionally created the misperception that women managers are "deficient" in skills, knowledge and expertise. When women comprise less than $15 \%$ of a total category in an organisation, they can be labelled as "tokens", i.e. as symbols of their group rather than as individuals (Kanter, 1977). The respondents who were regarded as being the 'token' black women managers identified the following stressors:

- High visibility (100\%);

- Being the first of their race and gender to hold a management position in the organisation $(100 \%)$;

- The pressures related to being a test case for the employment of future black women in the company at management level $(100 \%)$.

The following remark reflects the difficulty organisations have in reconciling an African female face with a management function:

Being different is viewed negatively as I do not conform to the stereotypical images of corporate managers. One of the comments made by my boss was 'You do not have the face of an accountant.

McDerment (1992:13) found that women managers constituted the major target group for stress-related diseases. People from black and ethnic minority groups were particularly vulnerable to dysfunctional stress. Not surprisingly, the pressures associated with being a token woman manager are often a tremendous burden, as illustrated by the following comments:

We often hear comments that we got the job because we are black women and not because we have the qualifications and experience to do the job. So the affirmative action policy, whilst being positive, also impacts negatively on our status.

Being the first black women manager, I am under constant pressure to perform well. If I do not perform well as a manager then I am letting all black women down.

Being a test case for the employment of future black women as managers in my company is a responsibility that is really stressing me out.

The present findings reflect that the African and Indian respondents experienced intensified negative effects associated with their tokenism compared to their Caucasian female counterparts. Irrespective of their qualifications, these token women were subject to excessive scrutiny, their differences from men became highlighted and polarised, and their attributes were distorted so that they became entrapped in stereotypical roles. By virtue of being placed in a group which was significantly outnumbered by men, female managers became tokens, which forced them into roles that limited their probability of success (Davidson, 1997).

\section{Social isolation}

Given the history of South Africa during the apartheid, women are under-represented at managerial levels. The majority of the respondents $(80 \%)$ were the only female managers in their department. The following stressors were identified by the respondents:

- Exclusion from networks $(80 \%)$;

- Lack of mentoring relationships $(90 \%)$;

- Lack of role models (90\%);

- Lack of social support (70\%);

- Exclusion from social outings with male colleagues and directors (90\%); 
- Social and recreational activities are not women-friendly, for example, golf tournaments, darts competitions, a night out in the pub ... (90\%).

Gender-specific models of career progression show that women advance more slowly than men and that factors influencing success in terms of hierarchical growth differ for the gender (Kirchmeyer, 1996). A very consistent difference was that men had role models, received mentoring and had extensive networks, which facilitated their career progression.

\section{RACE AND STRESS}

There is more to understanding stress and stress management than an analysis of organisational and personal factors. Social factors such as racism and ethnicity also play a key role in identifying female managers' vulnerability to stress. Given the racial composition of the sample, the researcher examined whether racial discrimination was a potential source of stress. The majority of the Indian respondents $(90 \%)$ in the public and private sectors experienced racial discrimination as a potential source of stress. All the African respondents (100\%) in the public and private sectors experienced racial discrimination as a potential source of stress. Racism operates in many and diverse ways, but the most common concerns noted were:

- Not being taken seriously because of colour $(60 \%)$;

- Isolation because of colour (60\%);

- Visibility because of colour (40\%);

- Lack of support from other race groups $(50 \%)$;

- Inter-race rivalry $(50 \%)$;

- The failure of the white directors to recognise the capabilities of the African and Indian respondents;

- Resistance by Caucasian staff to being managed by African or Indian women managers $(60 \%)$.

The stress of being a black manager in a predominately white setting was highlighted by one of the respondents: "As a black woman I feel very stressed out working in an organisation based on white and male models of work which were inherited from the apartheid era. I do not 'fit in' with the corporate images of the people in management, which is predominantly white males."

Racism was not only identified as a life pressure at a general level by the respondents but also as a specific occupational stressor which resulted from role ambiguity and dilemmas inherent in such situations. What often made such incidents even more potentially stressful was the lack of support from the management and Caucasian colleagues as reflected by the following comments:

As a black manager supervising white staff, I have often felt isolated, rejected, humiliated and unsupported, especially when dealing with staff that is racist.

My institution is referred to as the "Cinderella institution". The management does not give me sufficient support and resources to run the institution as all the children in the institution are black. They do not have proper bedding, ablution facilities and clothing. Rotten vegetables and left-overs from the white institutions are sent to me. Although I have motivated for resources, these requests are often ignored.

I am the only black woman in a boardroom full of white staff and management does not provide me with any resources that I fight for in the boardroom. I do not get any support from my white female colleagues either in the boardroom. 
The following remarks reflect the difficulty organisations have in reconciling an African or Indian female face with the management function:

Being different is viewed negatively as I do not conform to the stereotypical images of corporate managers. One of the comments made by my boss was "You do not have the face of an accountant”.

That short black woman ... what can she do besides making tea? I was told that I do not look the part of an executive by my management.

That black woman that came from the outside knows nothing about my job. She is just a "window dressing" and I have to suffer the consequences of affirmative action. I am working for several years in the company and I should have got the promotion. Instead I have to be under her. This is ludicrous.

Thus the strains of coping with racism resulted in stress. The present findings clearly illustrate the failure of organisations to respond to the presence of African and Indian women in management. Similarly, Davidson (1997) found that black and Indian women managers in the United Kingdom were subject to racial discrimination and the strain of coping with racism led to stress.

\section{Performance pressure because of colour}

One of the stressors most frequently cited by the respondents concerned performance pressure because of colour. All the African and Indian respondents experienced the pressure to perform because of their colour. Some of the concerns noted were:

- Having to prove themselves more than their Caucasian colleagues (90\%);

- Having to work harder and meet higher performance levels than their Caucasian colleagues $(100 \%)$;

- Constantly justifying professional status ((90\%);

- High expectations (100\%);

- Expecting respondents to fail $(90 \%)$.

One respondent commented: "I am not given credit and recognition for my professional qualifications and expertise. My board only sees me as a black woman. As a result of this I am constantly under pressure to perform well and prove that black women are capable of holding executive positions."

Another respondent commented: "I am the only Indian female manager in my department and I have to work harder than my male counterparts and be on top of things to prove that I am capable of managing. Yet my Caucasian male colleagues do not work as hard as I do, but still get more recognition than I do."

\section{DISCUSSION OF FINDINGS}

It is evident from the present findings that there is a re-segregation of the labour market in terms of both "race" and "gender" in both the public and private organisations. The respondents experienced similar sources of stress arising from race and gender discrimination both in the private and public sectors. However, compared to their Caucasian counterparts, the African and Indian respondents experienced the double bind of racism and sexism, thus increasing their vulnerability to stress. 
One of the major stressors experienced by the respondents was stereotyping based on race and gender. Stereotyping within firms leads to attribution errors, such as all successes by women managers are situational luck and all failures reflect women's inherent inabilities to function as managers. In other words, women are not born to be leaders. The social psychological literature on stereotyping and status expectations is quite clear that in the absence of strong information to counter stereotypes, prejudgments rule. Even employers report that they use race as a signal for potential productivity (Reskin, 1998). Appointing women of all races into management positions in the $21^{\text {st }}$ century is generally accepted as a reasonable principle in South Africa. The contradiction between this principle of equality and the demonstrable inequalities evident in this study exposes the continuing dominance of male privilege and values throughout society (patriarchy). Women managers themselves have to make sure that this process towards employment equity is a success by repositioning themselves to meet the challenges of the $21^{\text {st }}$ century. Given the nature of the stressors experienced by women managers, it will take more than legislation to eradicate the social ills of racism and sexism at work. The main challenge for South Africa is bridging the gap between policy and practice. Both public and private sector organisations need to address "racial and gendered" organisational cultures.

Managers in South Africa need to extract the best management tools from camps representing a variety of cultural management orientations both within and outside. Madi (1995) points out that the issue is not that there should be an Africanisation of the corporate culture in South Africa, but there should be South Africanisation of the corporate culture. In the debate on Afrocentric versus Eurocentric management styles Beaty (1996:397) states: "One cannot but observe the striking parallels between and the complementary nature of the feminine and the Afro-centric leadership approaches, which are already reflected in the South African situation. This just emphasises the dictum: Unity in Diversity". Thus, in order to empower South African organisations to compete in today's highly competitive, global marketplace, it is critical to have a diverse and flexible leadership team that includes feminine and masculine as well as Eurocentric and Afro-centric strengths.

Given the nature of stress arising from racism and sexism, social workers in working with executive stress amongst women should ensure that the following paths be paved to understand and lessen the inequality organizations generate:

- Study the workplace inequality processes that create cumulative skill inequalities;

- Discussion with employers and staff about gender and racial discrimination and stereotyping;

- Dialogue between organisations and women managers about boundaries, inclusion and exclusion at work;

- Study the spatial and historical variability of racial and gender inequality;

- Promote anti-oppressive practices in organisations;

- Ensure that the desired goals of the affirmative action policy of racial and gender equality in the workplace are achieved.

The key question is not: "What are the human capital deficits of female managers?" The question we should be asking is: "What are the workplace, community and family processes which generate racial and gender inequality?" One should search for answers in stereotyping, social closure, historically embedded racism, sexism, opportunity, career processes and stressors which they produce. 


\section{REFERENCES}

BEATY, D.T. 1996. Eurocentric or Afrocentric? Business Day: Mastering Management Series, Part 2, 11/03.

DAVIDSON, M.J. 1997. The black and ethnic minority woman manager: cracking the concrete ceiling. London: Paul Chapman Publishing Ltd.

DAVIDSON, M.J. \& COOPER, C.L. 1992. Shattering the glass ceiling: the woman manager. London: Chapman.

DAVIDSON, M.J. \& BURKE, R. J. (eds) 2000. Women in management: current research issues (Vol 11). London: Sage Publications.

DEPARTMENT OF LABOUR 1998. Employment Equity Act No. 55 of 1998. [Online] Available: http://www.labourgov.za. [Accessed: 30/05/2009].

HANNER, J. \& STATHAM, D. 1988. Women and social work. London: MacMillan.

KANTER, R. 1977. Men and women of the corporation. In: DAVIDSON, M.J. The black and ethnic minority woman manager: cracking the concrete ceiling. London: Paul Chapman Publishing Ltd.

KIRCHMEYER, C. 1996. Determinants of managerial career success, firm evidence and explanation of male/female differences. Wayne State University: Academy of Management.

MADI, P. 1995. Moving the Centre. People Dynamics, 13(3):12-16.

McDERMENT, L. 1992. Present tense, future perfect. In: THOMPSON, N., MURPHY, M. \& STRADLING, S. Dealing with stress. Hong Kong: MacMillan Press Ltd.

MORNA, C.L. 2009. In South Africa, women still are underdogs in the media. [Online] Available: http://www.afrol.com/articles/25318. [Accessed: 30/05/2009].

PERRAULT, M.R. \& IRWIN, J.K. 1996. Gender differences at work. Are men and women really that different? Analysis and findings from a study of women and men. [Online] Available: http://www.ateamware.com,AdvancedTeamware Inc. [Accessed: 30/07/2008].

PILLAY, J.K. 2000 Women, work and family life: a case study of Indian South Africans. Durban: University of Durban-Westville. (PhD Dissertation)

POWELL, G.N. 2000. The glass ceiling: explaining the good and bad news. In: DAVIDSON, M.J. \& BURKE, R.J. (eds) Women in management: current research issues (Vol 11). London: Sage Publications.

RESKIN, B. 1998. The realities of affirmative action in employment. Washington, D.C.: American Sociological Association.

SIEGRIST, J. 1996. Adverse health effects of high effort/low reward conditions. Journal of Occupational Health Psychology, 1(1):27-41.

SIEGRIST, J. \& PETER, R. 2000. The effort-reward imbalance model. In: SCHNALL, P.L., BELKIC, K., LANDSBERGIS, P. \& BAKER, D. (eds) State of the Art Reviews. Occupational Medicine: The Workplace And Cardiovascular Disease, 15:83-87. Philadelphia: Hanley and Belfus, Inc. 
SOUTH AFRICAN WOMEN IN CORPORATE LEADERSHIP CENSUS. 2004. Census shows women progressing in top jobs. [Online] Available: http://www.bwasa.co.za/docs. [Accessed: 30/07/2008].

SWANEPOEL, B. 2000. South African human resource management: theory and practice. Cape Town: Juta \& Co Ltd.

VINNICOMBE, S. 2000 The position of women in management in Europe. In: DAVIDSON, M.J. (eds) Black and ethnic minority woman manager: cracking the concrete ceiling. London: Paul Chapman Publishing Ltd.

WILKINSON, R.G. 1996. Unhealthy societies: the afflictions of inequality. London: Routledge.

Dr Gourie Suraj-Narayan, School of Social Work and Community Development, University of KwaZulu-Natal, Durban, South Africa. 